\title{
Sheep as a new experimental host for Babesia divergens
}

\author{
Alain CHAUVIN ${ }^{\mathrm{a} *}$, Alexis VALENTIN ${ }^{\mathrm{b}}$, Laurence MALANDRIN ${ }^{\mathrm{a}}$, \\ Monique L'Hostis a \\ a UMR ENVN/INRA 1034, Interactions Hôte-Parasite-Milieu, École Nationale Vétérinaire \\ de Nantes, Atlanpole-La Chantrerie, BP 40706, 44307 Nantes Cedex 03, France \\ b Laboratoire de Parasitologie-Immunologie, Faculté de Pharmacie, \\ Université de Montpellier, France
}

(Received 14 September 2001; accepted 6 March 2002)

\begin{abstract}
Babesia divergens was cultivated in sheep erythrocytes in RPMI 1640 supplemented with $10 \%$ Fetal Calf Serum (FCS) or sheep serum. In vitro cultures in sheep red blood cells were initiated with human erythrocytes infected in vitro with $B$. divergens Rouen 1987 or with gerbil blood infected with several isolates from bovine origin. After the first subcultures on sheep erythrocytes, a ten-fold multiplication of the parasites was obtained within $48 \mathrm{~h}$. Erythrocytes from three splenectomized sheep were infected in vitro with $B$. divergens; when parasitaemia reached $10 \%$, the animals were inoculated with homologous parasitized erythrocytes. All sheep expressed hyperthermia with a peak between the 6 th and the 9 th day post-infection $(\mathrm{p}-\mathrm{i})$ and a transitory parasitaemia 10 days $\mathrm{p}-\mathrm{i}$. In vitro primary cultures were performed on two of these sheep, demonstrating the parasite persistence at very low parasitaemia in the infected animals. Splenectomized sheep can be used as a new model for $B$. divergens chronic infection.
\end{abstract}

\section{Babesia divergens / sheep / in vitro culture / experimental infection}

Résumé - Le Mouton : un nouvel hôte expérimental de Babesia divergens. Babesia divergens a été cultivé in vitro dans des hématies de Mouton suspendues dans du RPMI 1640 supplémenté par $10 \%$ de sérum de veau foetal ou de sérum de Mouton. Les cultures en hématies de mouton ont été initiées avec des hématies humaines infectées in vitro par B. divergens Rouen 1987 ou avec des hématies de gerbilles infectées par différents isolats d'origine bovine. Après les premiers passages sur hématies de mouton, les parasites se multiplient 10 fois en $48 \mathrm{~h}$. Les hématies de trois moutons splénectomisés ont été infectées in vitro par $B$. divergens ; lorsque la parasitémie in vitro a atteint $10 \%$, les animaux ont été infectés expérimentalement avec les hématies homologues. Tous les moutons ont présenté un pic d'hyperthermie entre le $6^{\mathrm{e}}$ et le $9^{\mathrm{e}}$ jour post-infection $(\mathrm{p}-\mathrm{i})$ et une parasitémie

* Correspondence and reprints

Tel.: (33) 2406876 98; fax: (33) 2406877 51; e-mail: chauvin@vet-nantes.fr 
transitoire 10 jours p-i. Des cultures in vitro primaires réalisées sur deux animaux ont démontré la persistance du parasite pendant 28 semaines. Le mouton splénectomisé peut être utilisé comme un nouveau modèle d'infection chronique par $B$. divergens.

Babesia divergens / mouton / culture in vitro / infection expérimentale

\section{INTRODUCTION}

Babesia divergens, transmitted by the three host ticks Ixodes ricinus, is the main causative agent of bovine babesiosis in Europe. It appears to be less host specific than the other Babesia species from domestic animals. $B$. divergens is responsible for most cases of human babesiosis in Europe [6], particularly in splenectomized people. Splenectomized rats could be experimentally infected by $B$. divergens [10], but the main experimental model for $B$. divergens babesiosis remains the Gerbil (Meriones unguiculatus), which develops an acute and fatal babesiosis [9]. The in vitro culture of $B$. divergens has also been described in erythrocytes from different origins: rat [1] and humans [5]. This paper presents the in vitro culture of $B$. divergens in sheep erythrocytes and the first results on experimental infections of splenectomized sheep with $B$. divergens.

\section{MATERIALS AND METHODS}

\subsection{B. divergens isolates}

B. divergens Rouen 1987 was obtained from a man who had recovered from acute babesiosis [5]. Additionally, five $B$. divergens isolates were obtained from infected cattle in 1988: 1903B (Corrèze), 2212B (Côtes d'Armor), 2704A (Eure), 3606A (Indre), 5601A (Morbihan). The different isolates were intraperitoneally injected into two gerbils successively before in vitro culture.

\subsection{Cryopreservation of $B$. divergens isolates}

Infected gerbil blood or in vitro culture were cryopreserved. Erythrocytes of parasitized gerbils or parasitized sheep erythrocytes were washed twice for $10 \mathrm{~min}$ at $1200 \mathrm{~g}$ with RPMI 1640 (Eurobio, Les Ulis, France); the pellet was then resuspended at $0{ }^{\circ} \mathrm{C}$ to obtain a final dilution of $25 \%$ erythrocytes, $47.5 \%$ RPMI 1640, $7.5 \%$ DMSO (SIGMA, St Quentin Fallavier, France) and 20\% Fetal Calf Serum (FCS, Eurobio); $0.5 \mathrm{~mL}$ aliquots in sterile ampoules were frozen to $-80^{\circ} \mathrm{C}$ in liquid isopropanol (SIGMA) for $16 \mathrm{~h}$ and stored in liquid nitrogen. To recover the frozen parasites, the ampoules were thawed in a $37^{\circ} \mathrm{C}$ water bath and the parasites were washed for $10 \mathrm{~min}$ at $1200 \mathrm{~g}$ in RPMI 1640 before infection of gerbils or initiation of the in vitro cultures.

\subsection{In vitro culture of Babesia divergens}

In vitro culture of $B$. divergens Rouen 1987 was initiated with infected gerbil blood cells and was first performed in human red blood cells as previously described [2]. The parasites were grown in $25 \mathrm{~cm}^{2}$ culture flasks, in $\mathrm{O}$ group erythrocytes suspended at 2.5\% haematocrit in RPMI 1640 (Eurobio) $\mathrm{pH} 7.3$ buffered by $25 \mathrm{mM}$ HEPES, $2.1 \mathrm{~g} / \mathrm{L} \mathrm{NaHCO}_{3}$ and supplemented with $10 \%$ human serum (AB Group). Cultures were performed in a humidified $6 \%$ $\mathrm{CO}_{2}$ atmosphere at $37^{\circ} \mathrm{C}$. The media were changed every two days until the parasitaemia reached $10 \%$ and daily when 
parasitaemia exceeded $10 \%$. For the subcultures, the infected erythrocytes were diluted to $1 \%$ with normal human erythrocytes.

In vitro culture in sheep erythrocytes of B. divergens Rouen 1987 was initiated from in vitro culture in human erythrocytes. In vitro culture in sheep erythrocytes of the five isolates of bovine origin were directly initiated with infected gerbil blood. The culture method was similar but the media was supplemented with FCS or sheep serum.

\subsection{Experimental infection of sheep}

Three 6-month-old male sheep were splenectomized under gas anaesthesia. The animals were infected at least three weeks after splenectomy. Infective material was produced by cultivating $B$. divergens Rouen 1987 on homologous red blood cells in sheep serum. An infective dose of $10^{9}$ to $5 \times 10^{9}$ parasitized erythrocytes diluted in $\mathrm{NaCl} 9 \%$ was intravenously injected. Sheep $n^{\circ} 1$ and $n^{\circ} 2$ were treated with dexamethasone at $0.5 \mathrm{mg} / \mathrm{kg}$ for 4 days after experimental infection. Rectal temperature and haematocrit were recorded daily for 15 days. For 2 sheep $\left(n^{\circ} 2\right.$ and $\left.n^{\circ} 3\right)$, in vitro primary cultures were performed for 28 weeks: the blood of infected sheep was collected on citrate dextrose phosphate (CPD, SIGMA) and centrifuged at $1100 \mathrm{~g}$ for $10 \mathrm{~min}$; $1 \mathrm{~mL}$ of packed red blood cells was suspended in culture media supplemented with $10 \%$ sheep serum and grown in $25 \mathrm{~cm}^{2}$ culture flasks. The culture medium was changed every 2 days until parasitaemia reached $10 \%$.

\section{RESULTS}

\subsection{In vitro culture}

In vitro culture of $B$. divergens Rouen 1987 in sheep erythrocytes was initiated with $10 \%$ of human erythrocytes at $10 \%$ parasitaemia. During the first subcultures, the multiplication of $B$. divergens in sheep erythrocytes was lower than in human erythrocytes (Tab. I). After the 7th subculture in sheep erythrocytes, a $10 \%$ parasitaemia was obtained within $48 \mathrm{~h}$. When in vitro culture was initiated with erythrocytes from parasitized gerbils, the 2nd passage was very long (Tab. I); after the 4th passage in sheep erythrocytes, a $10 \%$ parasitaemia was obtained within $48 \mathrm{~h}$ (Fig. 1). For all the $B$. divergens isolates, parasitaemia of $50-60 \%$ could be reached in vitro in 72 to $96 \mathrm{~h}$ of culture.

Table I. Number of days needed to obtain a 10\% parasitaemia during the first in vitro subcultures (SC) for the different $B$. divergens isolates; SC were initiated with $1 \%$ of parasitized erythrocytes (in vitro parasitized human erythrocytes for the $\mathrm{SC} 1$ of $B$. divergens Rouen 87 , infected gerbil erythrocytes for the $\mathrm{SC} 1$ of the other isolates, in vitro parasitized sheep erythrocytes for the other subcultures).

\begin{tabular}{cccccccc}
\hline & SC 1 & SC 2 & SC 3 & SC 4 & SC 5 & SC 6 & SC 7 \\
\hline Rouen 87 & $\mathbf{4}$ & $\mathbf{4}$ & $\mathbf{4}$ & $\mathbf{4}$ & $\mathbf{4}$ & $\mathbf{3}$ & 2 \\
$\mathbf{1 9 0 3 B}$ & $\mathbf{2}$ & $\mathbf{1 4}$ & $\mathbf{1 1}$ & $\mathbf{3}$ & 2 & 2 & 2 \\
$\mathbf{2 2 1 2 B}$ & $\mathbf{7}$ & $\mathbf{1 4}$ & $\mathbf{3}$ & 2 & 2 & 2 & 2 \\
2704A & $\mathbf{2}$ & $\mathbf{1 4}$ & $\mathbf{6}$ & 2 & 2 & 2 & 2 \\
3606A & $\mathbf{2}$ & $\mathbf{1 8}$ & $\mathbf{8}$ & 2 & 2 & 2 & 2 \\
$\mathbf{5 6 0 1 A}$ & $\mathbf{2}$ & $\mathbf{1 4}$ & $\mathbf{6}$ & 2 & 2 & 2 & 2 \\
\hline
\end{tabular}




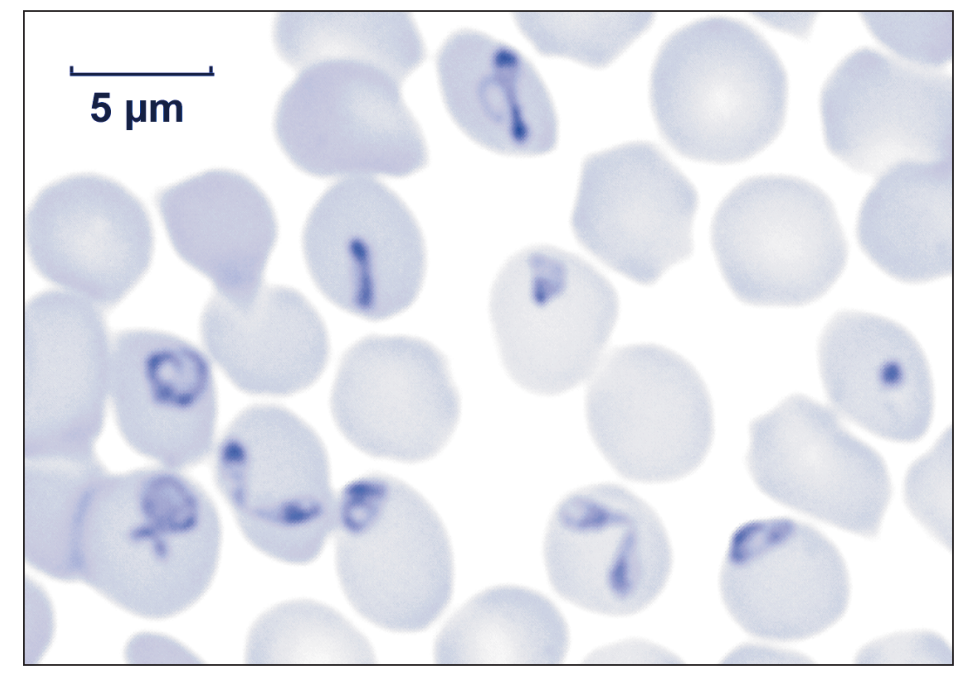

Figure 1. In vitro culture in sheep erythrocytes of $B$. divergens Rouen 1987.

The cultures could be stored frozen in liquid nitrogen and reactivated in vitro without any reinfection of gerbils (data not shown).

\subsection{Experimental infection $\mathbf{f}$ sheep}

The 3 sheep expressed hyperthermia with a peak between the 6th and the 9th day post-infection (p-i). A transitory parasitaemia was observed on stained blood smears the 10th day p-i for sheep n $n^{\circ}$ and $n^{\circ} 3(1 \%)$ and between the 9th and the 12th day $\mathrm{p}$-i for sheep $\mathrm{n}^{\mathrm{o}} 1$ (maximum $3 \%$ on day $\left.10 \mathrm{p}-\mathrm{i}\right)$. The in vitro primary cultures performed on sheep $\mathrm{n}^{\mathrm{o}} 2$ and 3 were positive during the 28 weeks; a $10 \%$ parasitaemia was reached after 6 to 10 days of culture between the 8th and the 12th day p-i; from the 2nd to the 28th week $\mathrm{p}-\mathrm{i}, 10 \%$ parasitaemia was reached in $16.2 \pm$ 0.8 days of culture ( 9 to 20 days).

\section{DISCUSSION}

The continuous culture of $B$. divergens was first described in bovine erythrocytes using the candle jar system $[3,12]$ and a medium supplemented with $40 \%$ bovine serum. The culture achieved parasitaemia of $5-15 \%$. The in vitro culture of $B$. bovis has been described in sheep, goat, horse and rabbit erythrocytes [11]. Similarly, Ben Musa and Phillips [1] and Gorenflot et al. [5] described continuous culture of $B$. divergens in rat erythrocytes and human erythrocytes respectively; they both used RPMI 1640 supplemented with $20 \%$ FCS and $10 \%$ human serum respectively. The culture in sheep erythrocytes described in this paper is closely related to these protocols. After 4 to 7 subcultures in sheep red blood cells, this culture system allowed high in vitro parasitaemia (50-60\%) and used only $10 \%$ FCS and a convenient source of red blood cells.

The culture could also be adapted to sheep serum and allowed the experimental infection of sheep with their own erythrocytes infected in vitro with $B$. divergens. The primary cultures from erythrocytes of experimentally infected animals demonstrated the parasite persistence at very low parasitaemia in the infected animals for at least 28 weeks. After experimental infection, gerbils develop an acute and fatal illness; they are commonly 
used as models for $B$. divergens babesiosis, notably to test the efficacy of vaccines [4, 7]. After natural infection, cattle do not always develop acute babesiosis; furthermore, they stay chronically infected [8]. In this study, after experimental infection, splenectomized sheep also became asymptomatic carriers of the parasite. Splenectomized sheep could then be used as a complementary model to evaluate the parasite persistence after administration of drugs or vaccine preparation. Furthermore, splenectomized sheep will be an efficient model of chronic babesiosis. This will enable the study of the in vivo interactions between different parasitic isolates and the transmission of $B$. divergens to Ixodes ricinus, since sheep are a normal host of the adult stage of these ticks.

\section{REFERENCES}

[1] Ben Musa N., Phillips R.S., The adaptation of three isolates of Babesia divergens to continuous culture in rat erythrocytes, Parasitology 103 (1991) 165-170.

[2] Brasseur Ph., Lecoublet S., Kapel N., Favennec L., Ballet J., In vitro evaluation of drug susceptibilities of Babesia divergens isolates, Antimicrob. Agents Chemother. 42 (1998) 818-820.

[3] Canning E.U., Winger C.M., Babesiidae, in Taylor A.E.R., Baker J.R. (Eds.), In vitro meth- ods for parasite cultivation, Academic Press, London, 1987, pp. 199-229.

[4] Gorenflot A., Precigout E., Bissuel G., Lecointre O., Brasseur P., Vidor E., L'Hostis M., Schrevel J., Identification of major Babesia divergens polypeptides that induce protection against homologous challenge in gerbils, Infect. Immun. 58 (1990) 4076-4082.

[5] Gorenflot A., Brasseur P., Precigout E., L'Hostis M., Marchand A., Schrevel J., Cytological and immunological responses to Babesia divergens in different hosts: ox, gerbil, man, Parasitol. Res. 77 (1991) 3-12.

[6] Gorenflot A., Carcy B., Moubri K., Precigout E., Schetters T., Les babésioses humaines, Méd. Mal. Infect. 28 (1998) 363-366.

[7] Grande N., Precigout E., Camillieri S., Carcy B., Moubri K., Gorenflot A., Comparison between aseric and seric culture-derived exoantigens of Babesia divergens in their ability to induce immunoprotection in gerbils, Parasitol. Int. 47 (1998) 269-279.

[8] Joyner L.P., Davies S.F.M., Acquired resistance to Babesia divergens in experimental calves, J. Protozool. 14 (1967) 260-262.

[9] Lewis D., Williams H., Infection of the Mongolian gerbil with the cattle piroplasm Babesia divergens, Nature 278 (1979) 170.

[10] Phillips R.S., Babesia divergens in splenectomized rats, Res. Vet. Sci. 36 (1984) 251-255.

[11] Ristic M., Levy M.G., A new era of research toward solution of bovine babesiosis, in: Ristic M., Kreier J.P. (Eds.), Babesiosis, Academic Press, London, 1981, pp. 509-544.

[12] Väyrynen R., Tuomi J., Continuous in vitro cultivation of Babesia divergens, Acta Vet. Scand. 23 (1982) 471-472. 